\title{
Review Article \\ The Female Pattern Hair Loss: Review of Etiopathogenesis and Diagnosis
}

\author{
Anja Vujovic and Véronique Del Marmol \\ Department of Dermatology, Hôpital Erasme, Université Libre de Bruxelles, Route de Lennik 808, Anderlecht, 1070 Brussels, Belgium \\ Correspondence should be addressed to Anja Vujovic; vujovic.anja@yahoo.com and Véronique Del Marmol; v.marmol@skynet.be
}

Received 11 November 2013; Accepted 14 January 2014; Published 9 April 2014

Academic Editor: Claudine Piérard-Franchimont

Copyright (C) 2014 A. Vujovic and V. Del Marmol. This is an open access article distributed under the Creative Commons Attribution License, which permits unrestricted use, distribution, and reproduction in any medium, provided the original work is properly cited.

\begin{abstract}
Female pattern hair loss (FPHL) is the most common hair loss disorder in women. Initial signs may develop during teenage years leading to a progressive hair loss with a characteristic pattern distribution. The condition is characterized by progressive replacement of terminal hair follicles over the frontal and vertex regions by miniaturized follicles, that leads progressively to a visible reduction in hair density. Women diagnosed with FPHL may undergo significant impairment of quality of life. FPHL diagnosis is mostly clinical. Depending on patient history and clinical evaluation, further diagnostic testing may be useful. The purpose of the paper is to review the current knowledge about epidemiology, pathogenesis, clinical manifestations, and diagnosis of FPHL.
\end{abstract}

\section{Definition of FPHL}

The FPHL is a nonscarring progressive thinning of hair. It results from a progressive decrease in the ratio of terminal hairs to shorter, thinner vellus hairs, a process known as follicular miniaturization [1]. This miniaturization follows usually a pattern distribution. In women, FPHL typically presents as a diffuse reduction in hair density over the frontal and vertex areas, but parietal and occipital regions may be involved [2].

\section{Terminology}

In the past, the term "androgenetic alopecia" (AGA) was the primary term used to refer to this condition in both men and women. The term "andro" from ancient Greek refers to male subjects and "genetic" referred to the contribution of heredity. Over the years, "female pattern hair loss" became the preferred term for this form of hair loss. This terminology helps to distinguish the different features of the condition in women versus men and shows the lack of clear hormonal contribution in many cases. Further, some authors use the terms "androgen-dependent FPHL" and "androgenindependent FPHL" to separate women who have FPHL due to androgen excess from those with normal androgen levels [3].

\section{Epidemiology}

FPHL is very common and increases with age in the Caucasian womenpopulations. In 2001, Norwood established the prevalence of FPHL at 19 percent in a series of approximately 1000 Caucasian women [4]. Although FPHL can occur at any time of life, the condition occurs the most following menopause. This age-related rise was clearly established in Norwood's series; FPHL was only detected in 4 of 121 women between the ages of 20 and 29 ( 3 percent), but in 41 of 140 women between the ages of 70 and 89 (29 percent) [4]. In a British study of 377 women, 38 percent of women over the age of 70 years had FPHL [5]. The prevalence of the condition seems to be lower in the Asian population [6,7]. A Korean study shows that the prevalence of FPHL in Korean women at all ages was only $5.6 \%$. Like in Caucasian women, this prevalence increases steadily with advancing age [7]. There 


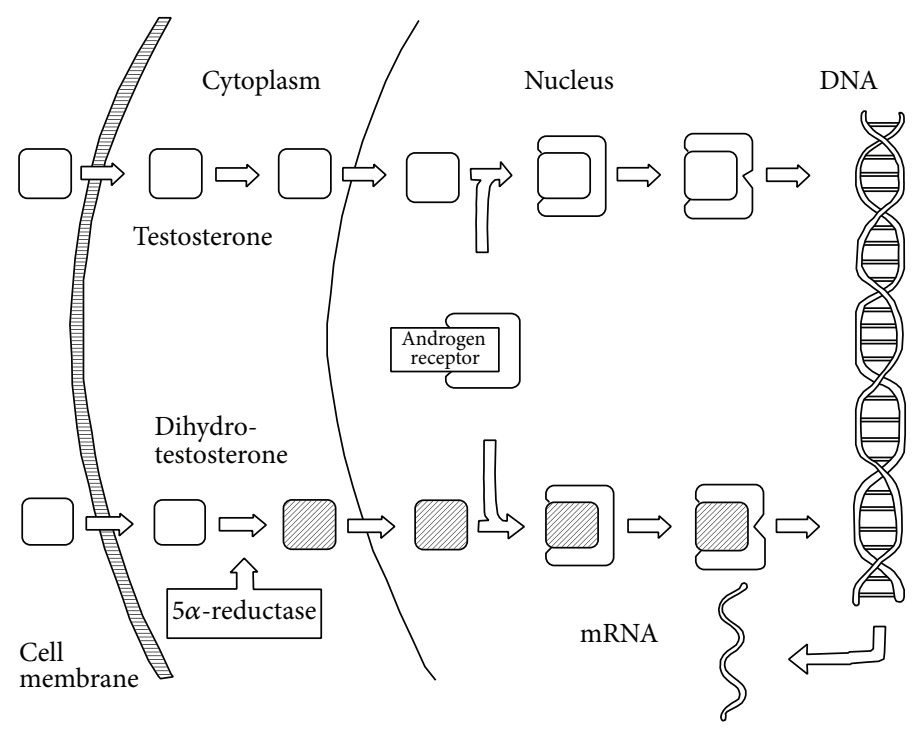

FIGURE 1: Schematic of the general mechanism of androgens action. Inside the cell, testosterone and DHT bind to the androgen receptor. Once the hormone has bound, the complex will bind to the DNA, altering the expression of specific androgens-dependent genes [10]. Reproduced by Thierry Huart.

are no published data over the prevalence of FPHL in African women.

\section{Etiology and Pathogenesis}

The visible thinning of hair of the scalp in FPHL results from a progressive decrease in the ratio of terminal hairs to shorter vellus hairs, a process called follicular miniaturization [8]. The mechanism through which this follicular transformation occurs in FPHL is not completely understood. Although the roles of androgens and genetic susceptibility in male AGA are well accepted, the degree to which these factors contribute to FPHL is less clear.

4.1. Androgens. The androgens role in common male baldness was first suspected by Hamilton in 1942 . He notes that AGA does not occur in men who have never entered puberty, that baldness stops its progression in castrated men, and that testosterone replacements stimulate progressive balding [9]. In recent studies, AGA is described as a consequence of the direct effects of dihydrotestosterone (DHT) on the dermal papilla of susceptible hair follicles [10]. DHT is a more potent androgen, coming from the metabolism of testosterone by the action of the $5 \alpha$-reductase. DHT binds to androgen receptors in hair follicles, more strongly even than testosterone, resulting in upregulation of genes responsible for the gradual transformation of terminal hair follicles to miniaturized hair follicles (Figure 1) [11]. These miniaturized hairs of various lengths and diameters are the hallmark of FPHL and AGA $[10,12,13]$. However, the number of follicles per unit area remains the same [14]. The pattern of hair loss, which typically spares the occipital scalp, reflects regional differences in the sensitivity of scalp follicles to androgens. Some authors have theorized that a similar process contributes to the development of FPHL, a concept supported by the observation that women with hyperandrogenism may develop earlyonset FPHL [2]. However, most women with FPHL have no other signs or symptoms of hyperandrogenism and have normal androgen levels, indicating that our understanding of the pathogenesis of the disorder remains incomplete. The age-related increase in FPHL and the highest rates in postmenopausal women may suggest a protective role of the estrogen. Supporting this theory, Sawaya and Price conducted a study in 12 young women and 12 young men (ages from 14 to 33) suffering from AGA or FPHL [15]. Scalp biopsies were taken and androgens, expression of androgen receptor, type I and type II $5 \alpha$-reductase, and cytochrome p-450 aromatase enzyme genes were measured in hair follicles. Both young women and young men had higher levels of type I and type II $5 \alpha$-reductase and androgen receptors in frontal hair follicles compared to occipital hair follicles explaining probably the patterned hair loss. However, the levels in women were approximately half the levels in men [15]. The findings of this study suggest that the milder expression of FPHL may in part be the result of lower levels of $5 \alpha$-reductase and androgen receptors in frontal follicles of women compared to levels in men. Additionally, young women had much higher levels of cytochrome p-450 aromatase, enzyme capable of converting testosterone to estradiol, in frontal and occipital follicles than men. Those notable increased aromatase levels seem to play a protective role in the development of hair loss in women [15]. Furthermore, supporting the androgendependent etiopathogenesis, low levels of sex hormonebinding protein (SHBG), glycoprotein that binds to androgens, inhibiting thereby their activities, have been linked to diffuse hair loss [16]. Another part of FPHL and AGA pathogenesis is the gradual shortening of the growth phase of hair follicles. Over the successive hair cycles, the duration of anagen phase shortens from a normal duration of a few years to only weeks to months [2]. 


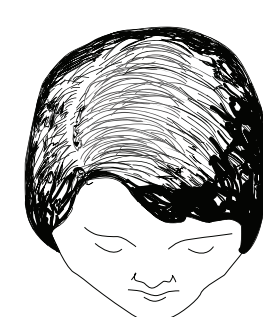

Type I

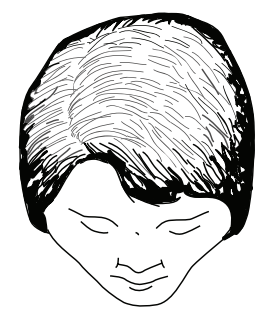

Type II

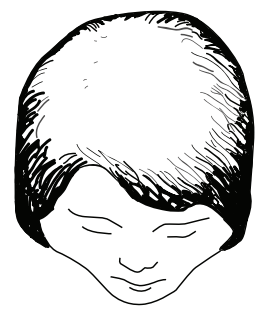

Type III
Figure 2: Ludwig pattern of hair loss in women. Three-point scale. Diffuse thinning of the crown region with preservation of the frontal hairline. Drawing by Thierry Huart based on Ludwig et al. [24, 25].

4.2. Genetics. There are few studies evaluating the genetic basis and inheritance pattern of FPHL [8]. One of them shows an incidence of $54 \%$ pattern hair loss in first-degree male relatives of age $>30$ years and $21 \%$ in first-degree female relatives $>30$ years. Those reports of the occurrence of both FPHL and AGA in individual families suggest that FPHL and AGA share a common genetic background $[17,18]$. The two major susceptibility loci for the AGA in men are the androgen receptor (AR)/ectodysplasin $\mathrm{A} 2$ receptor (EDA2R) locus on the X-chromosome and a locus on chromosome 20p11, for which no candidate gene has yet been identified $[19,20]$. Very recent studies show no involvement of the well-established locus on chromosome 20p11 in FPHL but suggested that the X-chromosomal locus containing the androgen receptor $(A R)$ and the ectodysplasin $\mathrm{A} 2$ receptor $(E D A 2 R)$ genes may be specifically involved in the pathogenesis of early-onset FPHL [21]. Moreover, an Australian genomewide association study suggested that the aromatase gene (CYP19A1) may contribute to FPHL [22].

\section{Clinical Features}

FPHL may have three different patterns [23]:

(1) diffuse thinning of the crown region with preservation of the frontal hairline: two scales are used to describe this pattern: the commonly 3-point Ludwig scale $[12,24]$ (Figure 2) and the 5-point Sinclair scale [25] (Figure 3);

(2) thinning and widening of the central part of the scalp with breach of frontal hairline, described by Olsen scale: Christmas tree pattern (Figure 4) [26];

(3) thinning associated with bitemporal recession; Hamilton-Norwood scale [27].

All these common patterns spare the occipital area, a phenomenon explained probably by hormonal influences explained above. This behavior's difference between the frontal/parietal follicles and the occipital follicles is found in other hair disorders like alopecia areata, a condition where occipital follicles affected by the ophiasis pattern are typically more resistant to regrowth [28]. These differences may result from the embryological derivation of the dermis in the two regions. It is known from avian embryology that the dermis of the frontal/parietal scalp is of neural crest origin, whereas the dermis of the occipital scalp is of mesodermal origin [29].

\section{Associated Disorders}

6.1. Psychosocial Dysfunction. Many women suffering from FPHL experience negative psychosocial effects related to the condition. In a questionnaire-based study, 70 percent of affected women reported that they were very to extremely upset about their hair loss. They experienced more feeling of negative image body and poorer self-esteem and had a less quality of life than the control group [30]. In another study, 88 percent of females with FPHL felt that the hair loss negatively influenced daily life [31]. Clinicians managing patients with FPHL should remain aware that the patient's perception of the severity of hair loss may be different from the clinical assessment of the severity and the psychosocial impact of the condition. In a recent questionnairebased study of 104 women suffering from different hair loss disorders like alopecia areata, FPHL, or telogen effluvium, the patient's perception of the severity of hair loss was greater than the severity ratings given by the dermatologist. In addition, the personal rating of hair loss will be more closely correlated with the effects of hair loss on quality of life [32]. This psychosocial dysfunction related to FPHL is also experienced by adolescent girls suffering from the condition. Those teenage girls may experience poor selfesteem and impaired functioning at home, school, or work and in personal relationships [33].

6.2. Medical Conditions. Links between early-onset FPHL and insulin resistance and hypertension and increased cardiovascular risk have been described $[34,35]$. Those conditions seem to be due to higher aldosterone, C-protein, Ddimers, and insulin levels in women suffering from FPHL than in control subjects. Authors recommend the determination of metabolic syndrome and ultrasound study of the carotid arteries to detect risk of developing cardiovascular disease in female patients with early-onset FPHL [35]. Recently, vertex pattern AGA in male patients of all ages was associated with an increased risk of prostate cancer [36]. There is no evidence in the current knowledge of an association between FPHL and the risk of any kind of cancer.

\section{Clinical Diagnosis}

7.1. General History. The physician should record age of onset and duration and progression of hair loss. The patients often describe a chronic hair loss with some increased periods of activity, particularly during autumn and winter. The patient should be asked about thinning and shedding. For thinning, most patients described an accentuation of the frontal, parietal, or vertex region, but a diffuse thinning is possible as well. The family history is more often positive, but a negative family history does not exclude the diagnosis. The patient should be asked about other familial hair disorders like alopecia areata or hirsutism, which may influence the further investigations. It is also important to exclude other 

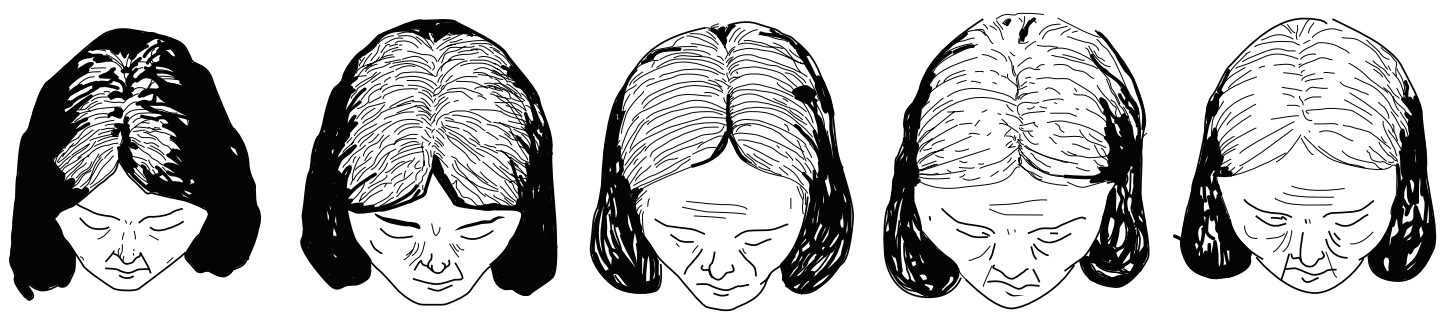

FIGURE 3: Sinclair scale: 5-point scale for grading of FPHL with diffuse thinning of the crown region with preservation of the frontal hairline. Drawing by Thierry Huart based on the Sinclair Scale, Sinclair et al. [25].
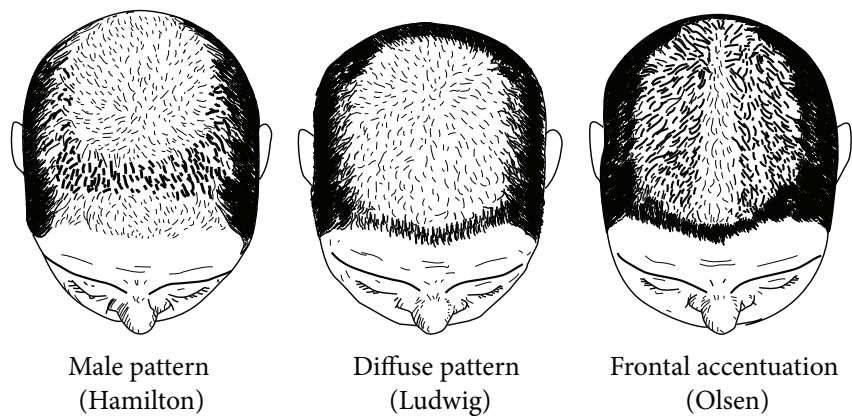

FIGURE 4: Olsen scale: Christmas tree pattern in female pattern hair loss. Thinning associated with bitemporal recession. Drawing by Thierry Huart based on Olsen scale, Olsen [26].

causes of hair loss whose untreated presence could affect the efficacy of the FPHL treatment. The presence of other medical disorders and newly diagnosed diseases within one year prior to first signs of hair loss and the medical treatment should be investigated. Other causes of hair loss such as diffuse effluvium due to iron deficiency, infection, thyroid dysfunction, or chronic deficient diet should be excluded. Some drugs such as chemotherapeutic agents, proandrogenic hormones, or antithyroids may cause diffuse hair loss. Moreover, some cosmetic habits (traction) or environmental factors like smoking [37] or UV-exposition [38] may induce increased hair loss in women. The experts all agree to ask about eating behavior, as chronic deficient diet or rapid important weight loss can trigger diffuse effluvium [23].

7.2. Gynecological History. A complete gynecological and obstetrical interrogatory that includes menarche, menstrual cycle (regular/irregular), menopause, amenorrhea, use of oral or systemic hormonal contraception, hormone replacement therapy, fertility treatment, problems in getting pregnant, gynecological surgery, pregnancies, births, miscarriages, and signs of hyperandrogenism (excessive body hair growth, acne, ect.) should be done to exclude influencing hormonal deregulations (e.g., hormone sensitive tumor) [39]. Impaired fertility, amenorrhea, irregular menstrual cycle, and signs of hyperandrogenism and hyperseborrhea may be indicative for polycystic ovary syndrome [40].

7.3. Physical Examination. A full skin examination that includes body and nails is advised in women complaining of hair loss. Nails abnormalities identification is not typical in
FPHL but may differentiate the condition from other cases of hair loss like alopecia areata, iron deficiencies, or lichen planus [23]. A whole body examination should be performed to find other signs of possibly associated hyperandrogenism.

7.4. Scalp and Hair Scalp Examination. Scalp examination should focus on identifying the distribution of hair loss and the caliber of hairs in commonly involved areas. Findings consistent with FPHL include the detection of terminal hair loss, variation of hair caliber, and miniaturized hairs. Pull test identifying increased shedding of telogen hairs is typically negative except in active phases of FPHL. The most frequently used scales are the Ludwig (Figure 2) and the Olsen (Figure 4) scales, described previously. FPHL is a nonscarring alopecia, explaining that the scalp skin appears normal, but other clinical features such as inflammation, scarring, or hyperseborrhea can be associated and potentially aggravating the FPHL [41]. The physician should also consider scarring alopecia mimicking FPHL like frontal fibrosing alopecia [42].

7.5. Trichoscopy. Trichoscopy or scalp dermatoscopy is a noninvasive diagnostic tool, very useful for the diagnosis and followup of hair and scalp disorders [43]. Trichoscopy of FPHL is characterized by hair diameter variability greater than 20\% [44] (Figure 5). Hair shaft variability can also be present in alopecia areata. However, in this pathology dermatoscopy shows uniform miniaturization instead of hair shafts with different degree of thinning. This hair diameter variability is very useful to detect early FPHL in children or teenage girls [45]. In 2009, Rakowska et al. [46] proposed major and minor dermoscopic criteria for the diagnosis of 


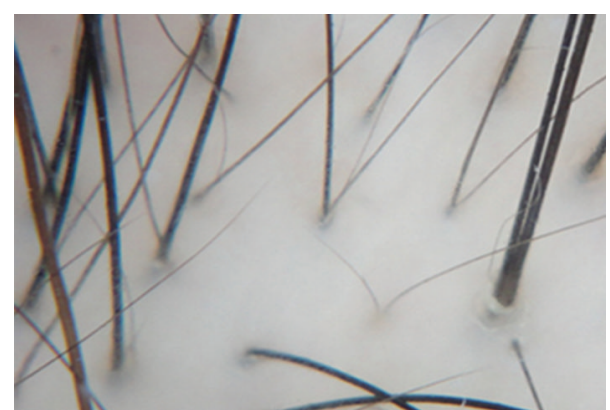

Figure 5: Trichoscopy of the frontal scalp in a female patient complaining of chronic hair loss. Trichoscopy shows FPHL: hair shaft variability greater than $10 \%$, vellus hairs, and perifollicular discoloration.

FPHL. Major criteria include (1) more than 4 yellow dots in 4 images in the frontal area; (2) lower average hair thickness in the frontal area compared with the occiput; and (3) more than $10 \%$ of thin hairs $(<0.03 \mathrm{~mm})$ in the frontal area. Minor criteria include (1) increased frontal to occipital ratio of single-hair pilosebaceous units; (2) vellus hairs; and (3) perifollicular discoloration. The diagnosis of FPHL is made during the presence of two major criteria or one major plus two minor criteria.

7.6. Pull Test. Pull test is a noninvasive diagnostic technique, very easy to perform and to repeat. Pull test is very helpful to rapidly determine the ongoing activity and severity of any kind of hair loss. Briefly, a bundle of about 50-60 hairs is grasped between the thumb, index finger, and middle finger from the base near the scalp. The hair is firmly, but not forcibly, tugged away from the scalp as fingers slide along the hair shaft [47]. The test is positive when more than $10 \%$ of the grasped hair (in average more than six hairs) can be pulled out [48]. If fewer than six hairs can be easily pulled out, this is considered normal physiologic shedding [49]. The test has a large interobserver variation and can be influenced by cosmetic habits, hair manipulation, and shampooing. Each clinician has to standardize his own procedure. The pull test should be done in all the scalp areas: right and left parietal, frontal, and occipital regions. A positive test present in more than one scalp region can be seen during a telogen effluvium. The patients suffering from FPHL may have a positive pull test only during the active phases in the affected area. A diffuse positive pull test requires always further investigation to exclude telogen effluvium [23].

\section{Other Diagnostic Techniques}

8.1. Scalp Biopsy. Scalp biopsy is an essential instrument in the diagnosis of cicatricial and selected forms of noncicatricial alopecia [50]. Although scalp biopsies are usually not needed to diagnose FPHL, they can be helpful if the clinical evaluation does not provide a definitive diagnosis, for example, when scalp changes suggestive of cicatricial alopecia of diffuse alopecia areata are present. A $4 \mathrm{~mm}$ punch extending into the subcutaneous fat should be performed on the central scalp area. It is best to avoid the bitemporal area as this region may have miniaturized hairs in women without hair loss [23]. Scalps biopsies should be read by experienced dermatopathologists using both vertical sectioning and horizontal sectioning. Horizontal sections allow a rapid evaluation of hair follicle number, diameter, grouping, and morphology maximizing the diagnostic yield [51]. In FPHL, there are an increased number of miniaturized (velluslike) hairs. The ratio of terminal to vellus-like hair follicles is typically $>3: 1$ in women suffering from this condition against $>7: 1$ in the normal scalp [14]. Other typical histopathological features are an increase of telogen:anagen ratio and an increased number of follicular stelae. A mild perifollicular inflammation around the upper portion of hair follicle as well as perifollicular fibrosis may also be seen [52].

8.2. Trichogram. The trichogram is a semi-invasive (plucking) microscopic method for hair root and hair cycle evaluation. The term "trichogram" was given by Pecoraro et al. in 1964, who described further trichometric parameters such as hair shaft diameter, hair growth, and telogen rate [53]. The trichogram is based on the hair cycle and quantifies hair follicles in their different growth phases: anagen, telogen, or catagen. Trichogram may be recommended in individual cases of FPHL if another diagnosis is suspected like an anagen-dysplastic effluvium or a loose anagen syndrome. Trichogram can also be useful as a complementary element that may confirm an early diagnosis of FPHL by showing inhomogeneous hair shafts. However, a recent study suggests that dermatoscopy is more useful for the diagnosis of FPHL than trichograms [54].

8.3. Phototrichogram/TrichoScan. Phototrichograms are automatic digitalized imaging techniques used to examine features of hair loss for diagnosis and followup [55]. A small area of the scalp is trimmed and followed with imaging. The proportion of anagen, telogen, and shed hairs as well as the rate of growth and the density can be recorded and compared [56]. The FPHL is characterized, like AGA, by a decrease in the frontal hair density compared with the occipital density. To ensure reproducibility tattoos identifying the studied area are required [48]. When available, those techniques are helpful for long-term followup and quantification, but currently they are mainly used as a tool for clinical studies [57].

8.4. Laboratory Tests. Ferritin and thyroid-stimulating hormone levels may be measured, especially in diffuse effluvium. The association between FPHL and low ferritin levels was suggested in two different studies $[58,59]$ which reported significantly lower ferritin levels in women suffering from FPHL compared with controls. More recent studies have not shown sufficient evidence of the relationship between low ferritin level and FPHL and do not recommend iron supplementation in the absence of deficiency anemia [60]. In 2008, Bregy and Trüeb even suggest no association between iron deficiency and hair loss in women [61]. The experts agreed that an extensive endocrinological investigation is not 
necessary in all women. Research for hyperandrogenic state will be performed in women with FPHL when the history and the clinical examination are suggesting an androgen excess (e.g., hirsutism, irregular menses, acne, and galactorrhea). Some authors speculate that the Hamilton IV pattern is more common in women suffering from ovarian hyperandrogenism, but there are no studies to corroborate or invalid this theory. The authors recommend a free androgen index test $\left(\mathrm{FAI}=\right.$ total testosterone $\left(\mathrm{nmolL}^{-1}\right) \times 100 /$ sex hormonebinding globulin (SHBG)) and prolactin as screening parameters for ovarian hyperandrogenism and dehydroepiandrosterone sulfate (DHEAs) and 17-hydroxyprogesterone (17-OH) as screening parameters for surrenal hyperandrogenism [23, 39, 62]. Depending on the results, further investigations may be needed and an interdisciplinary approach involving gynecologists, endocrinologists, and dermatologists may be required. Note that androgen levels testing should be done during the follicular phase, between the fourth and the seventh day of the cycle and that oral contraceptives should be discontinued for at least two months prior to this testing [63]. The patients should be informed that cessation of contraception may induce a three-month lasting telogen effluvium.

\section{Summary}

FPHL is a very common, nonscarring form of hair loss that can occur in all ages but most commonly in postmenopausal women. Although hormonal factors and genetic predisposition are believed to contribute to FPHL, the complete mechanism remains elusive and the most affected women have normal androgen levels. FPHL does not cause physical discomfort but the hair loss can contribute to significant psychological distress. Generally, the condition is clinical diagnosis, suggested by the reduction in hair density with a characteristic distribution. Depending on patient history and clinical evaluation, further diagnostic tests may be required.

\section{Disclosure}

Thierry Huart is Medical Illustrator.

\section{Conflict of Interests}

The authors declare that there is no conflict of interests regarding the publication of this paper.

\section{References}

[1] A. G. Messenger and R. Sinclair, "Follicular miniaturization in female pattern hair loss: clinicopathological correlations," British Journal of Dermatology, vol. 155, no. 5, pp. 926-930, 2006.

[2] V. H. Price, "Androgenetic alopecia in women," Journal of Investigative Dermatology Symposium Proceedings, vol. 8, no. 1, pp. 24-27, 2003.

[3] N. Atanaskova Mesinkovska and W. F. Bergfeld, "Hair: what is new in diagnosis and management? Female pattern hair loss update: diagnosis and treatment," Dermatologic Clinics, vol. 31, no. 1, pp. 119-127, 2013.
[4] O. T. Norwood, "Incidence of female androgenetic alopecia (female pattern alopecia)," Dermatologic Surgery, vol. 27, no. 1, pp. 53-54, 2001.

[5] M. P. Birch, J. F. Messenger, and A. G. Messenger, "Hair density, hair diameter and the prevalence of female pattern hair loss," British Journal of Dermatology, vol. 144, no. 2, pp. 297-304, 2001.

[6] T. L. Wang, C. Zhou, Y. W. Shen et al., "Prevalence of androgenetic alopecia in China: a community-based study in six cities," British Journal of Dermatology, vol. 162, no. 4, pp. 843-847, 2010.

[7] J.-H. Paik, J.-B. Yoon, W.-Y. Sim, B.-S. Kim, and N.-I. Kim, “The prevalence and types of androgenetic alopecia in Korean men and women," British Journal of Dermatology, vol. 145, no. 1, pp. 95-99, 2001.

[8] L. Yip, N. Rufaut, and R. Sinclair, "Role of genetics and sex steroid hormones in male androgenetic alopecia and female pattern hair loss: an update of what we now know," Australasian Journal of Dermatology, vol. 52, no. 2, pp. 81-88, 2011.

[9] J. B. Hamilton, "The relationship between common baldness and male sex hormones," Transactions of the New York Academy of Sciences, vol. 8, p. 101, 1946.

[10] D. A. Whiting, "Possible mechanisms of miniaturization during androgenetic alopecia or pattern hair loss," Journal of the American Academy of Dermatology, vol. 45, supplement 3, pp. S81-S86, 2001.

[11] P. Vexiau, C. Chaspoux, P. Boudou et al., "Role of androgens in female-pattern androgenetic alopecia, either alone or associated with other symptoms of hyperandrogenism," Archives of Dermatological Research, vol. 292, no. 12, pp. 598-604, 2000.

[12] E. A. Olsen, "Female pattern hair loss," Journal of the American Academy of Dermatology, vol. 45, supplement 3, pp. S70-S80, 2001.

[13] E. A. Olsen, Disorders of Hair Growth: Diagnosis and Treatment, vol. 12, McGraw-Hill, New York, NY, USA, 1994.

[14] D. A. Whiting, "Diagnostic and predictive value of horizontal sections of scalp biopsy specimens in male pattern androgenetic alopecia," Journal of the American Academy of Dermatology, vol. 28, no. 5, pp. 755-763, 1993.

[15] M. E. Sawaya and V. H. Price, "Different levels of $5 \alpha$-reductase type I and II, aromatase, and androgen receptor in hair follicles of women and men with androgenetic alopecia," Journal of Investigative Dermatology, vol. 109, no. 3, pp. 296-300, 1997.

[16] J. A. Miller, C. R. Darley, and K. Karkavitsas, "Low sex-hormone binding globulin levels in young women with diffuse hair loss," British Journal of Dermatology, vol. 106, no. 3, pp. 331-336, 1982.

[17] D. R. Nyholt, N. A. Gillespie, A. C. Heath, and N. G. Martin, "Genetic basis of male pattern baldness," Journal of Investigative Dermatology, vol. 121, no. 6, pp. 1561-1564, 2003.

[18] W. Küster and R. Happle, "The inheritance of common baldness: two B or not two B?" Journal of the American Academy of Dermatology, vol. 11, no. 5, part 1, pp. 921-926, 1984.

[19] F. F. Brockschmidt, A. M. Hillmer, S. Eigelshoven et al., "Fine mapping of the human AR/EDA2R locus in androgenetic alopecia," British Journal of Dermatology, vol. 162, no. 4, pp. 899903, 2010.

[20] A. M. Hillmer, S. Hanneken, S. Ritzmann et al., "Genetic variation in the human androgen receptor gene is the major determinant of common early-onset androgenetic alopecia," American Journal of Human Genetics, vol. 77, no. 1, pp. 140-148, 2005.

[21] S. Redler, F. F. Brockschmidt, R. Tazi-Ahnini et al., "Investigation of the male pattern baldness major genetic susceptibility 
loci AR/EDA2R and 20p11 in female pattern hair loss," British Journal of Dermatology, vol. 166, no. 6, pp. 1314-1318, 2012.

[22] L. Yip, S. Zaloumis, D. Irwin et al., "Gene-wide association study between the aromatase gene (CYP19A1) and female pattern hair loss," The British Journal of Dermatology, vol. 161, no. 2, pp. 289294, 2009.

[23] U. Blume-Peytavi, A. Blumeyer, A. Tosti et al., "S1 guideline for diagnostic evaluation in androgenetic alopecia in men, women and adolescents," British Journal of Dermatology, vol. 164, no. 1, pp. 5-15, 2011.

[24] E. Ludwig, "Classification of the types of androgenetic alopecia (common baldness) occurring in the female sex," British Journal of Dermatology, vol. 97, no. 3, pp. 247-254, 1977.

[25] R. Sinclair, D. Jolley, R. Mallari, and J. Magee, “The reliability of horizontally sectioned scalp biopsies in the diagnosis of chronic diffuse telogen hair loss in women," Journal of the American Academy of Dermatology, vol. 51, no. 2, pp. 189-199, 2004.

[26] E. A. Olsen, "Current and novel methods for assessing efficacy of hair growth promoters in pattern hair loss," Journal of the American Academy of Dermatology, vol. 48, no. 2, pp. 253-262, 2003.

[27] J. B. Hamilton, "Patterned loss of hair in man; types and incidence," Annals of the New York Academy of Sciences, vol. 53, no. 3, pp. 708-728, 1951.

[28] B. Werner and F. Mulinari-Brenner, "Clinical and histological challenge in the differential diagnosis of diffuse alopecia: female androgenetic alopecia, telogen effluvium and alopecia areatapart II," Anais Brasileiros de Dermatologia, vol. 87, no. 6, pp. 884890, 2012.

[29] C. Ziller, "Pattern formation in neural crest derivatives," in Hair Research for the Next Millenium, R. V. Dvan Neste, Ed., pp. 1923, Elsevier, Amsterdam, The Netherlands, 1996.

[30] T. F. Cash, "The psychosocial consequences of androgenetic alopecia: a review of the research literature," British Journal of Dermatology, vol. 141, no. 3, pp. 398-405, 1999.

[31] J. Van der Donk, J. A. M. Hunfeld, J. Passchier, K. J. Knegt-Junk, and C. Nieboer, "Quality of life and maladjustment associated with hair loss in women with alopecia androgenetica," Social Science and Medicine, vol. 38, no. 1, pp. 159-163, 1994.

[32] E. E. Reid, A. C. Haley, J. H. Borovicka et al., "Clinical severity does not reliably predict quality of life in women with alopecia areata, telogen effluvium, or androgenic alopecia," Journal of the American Academy of Dermatology, vol. 66, no. 3, pp. e97-e102, 2012.

[33] V. H. Price, "Androgenetic alopecia in adolescents," Cutis, vol. 71, no. 2, pp. 115-121, 2003.

[34] S. Arias-Santiago, M. T. Gutiérrez-Salmerón, L. CastelloteCaballero, A. Buendía-Eisman, and R. Naranjo-Sintes, "Androgenetic alopecia and cardiovascular risk factors in men and women: a comparative study," Journal of the American Academy of Dermatology, vol. 63, no. 3, pp. 420-429, 2010.

[35] S. Arias-Santiago, M. T. Gutiérrez-Salmerón, A. BuendíaEisman, M. S. Girón-Prieto, and R. Naranjo-Sintes, "Hypertension and aldosterone levels in women with early-onset androgenetic alopecia," British Journal of Dermatology, vol. 162, no. 4, pp. 786-789, 2010.

[36] A. Amoretti, H. Laydner, and W. Bergfeld, "Androgenetic alopecia and risk of prostate cancer: a systematic review and metaanalysis," Journal of the American Academy of Dermatology, vol. 68, no. 6, pp. 937-943, 2013.
[37] L. H. Su and T. H. Chen, "Association of androgenetic alopecia with smoking and its prevalence among Asian men: a community-based survey," Archives of Dermatology, vol. 143, no. 11, pp. 1401-1406, 2007.

[38] R. M. Trüeb, "Is androgenetic alopecia a photoaggravated dermatosis?” Dermatology, vol. 207, no. 4, pp. 343-348, 2003.

[39] U. Blume-Peytavi, S. Atkin, J. Shapiro et al., "European consensus on the evaluation of women presenting with excessive hair growth," European Journal of Dermatology, vol. 19, no. 6, pp. 597-602, 2009.

[40] H. Mason, A. Colao, U. Blume-Peytavi et al., "Polycystic ovary syndrome (PCOS) trilogy: a translational and clinical review," Clinical Endocrinology, vol. 69, no. 6, pp. 831-844, 2008.

[41] C. Piérard-Franchimont, V. Goffin, F. Henry, I. Uhoda, C. Braham, and G. E. Piérard, "Nudging hair shedding by antidandruff shampoos. A comparison of $1 \%$ ketoconazole, $1 \%$ piroctone olamine and $1 \%$ zinc pyrithione formulations," International Journal of Cosmetic Science, vol. 24, no. 5, pp. 249-256, 2002.

[42] S. Kossard, "Postmenopausal frontal fibrosing alopecia: scarring alopecia in a pattern distribution," Archives of Dermatology, vol. 130, no. 6, pp. 770-774, 1994.

[43] A. F. Pedrosa, P. Morais, C. Lisboa, and F. Azevedo, "The importance of trichoscopy in clinical practice," Dermatology Research and Practice, vol. 2013, Article ID 986970, 3 pages, 2013.

[44] O. de Lacharrière, C. Deloche, C. Misciali et al., "Hair diameter diversity: a clinical sign reflecting the follicle miniaturization," Archives of Dermatology, vol. 137, no. 5, pp. 641-646, 2001.

[45] A. Tosti, M. Iorizzo, and B. M. Piraccini, "Androgenetic alopecia in children: report of 20 cases," British Journal of Dermatology, vol. 152, no. 3, pp. 556-559, 2005.

[46] A. Rakowska, M. Slowinska, E. Kowalska-Oledzka, M. Olszewska, and L. Rudnicka, "Dermoscopy in female androgenic alopecia: method standardization and diagnostic criteria," International Journal of Trichology, vol. 1, no. 2, pp. 123-130, 2009.

[47] M. Guarrera, M. T. Semino, and A. Rebora, "Quantitating hair loss in women: a critical approach," Dermatology, vol. 194, no. 1, pp. 12-16, 1997.

[48] K. Hillmann and U. Blume-Peytavi, "Diagnosis of hair disorders," Seminars in Cutaneous Medicine and Surgery, vol. 28, no. 1, pp. 33-38, 2009.

[49] J. Shapiro, M. Wiseman, and H. Lui, "Practical management of hair loss," Canadian Family Physician, vol. 46, pp. 1469-1477, 2000.

[50] R. Sinclair, D. Jolley, R. Mallari et al., "Morphological approach to hair disorders," Journal of Investigative Dermatology Symposium Proceeding, vol. 8, no. 1, pp. 56-64, 2003.

[51] D. M. Elston, M. L. McCollough, and V. L. Angeloni, "Vertical and transverse sections of alopecia biopsy specimens: combining the two to maximize diagnostic yield," Journal of the American Academy of Dermatology, vol. 32, no. 3, pp. 454-457, 1995.

[52] E. A. Olsen and U. Blume-Peytavi, Hair Growth and Disorders, vol. 26, Springer, Berlin, Germany, 2008.

[53] V. Pecoraro, I. Astore, J. Barman, and C. Ignacio Araujo, "The normal trichogram in the child before the age of puberty," The Journal of investigative dermatology, vol. 42, pp. 427-430, 1964.

[54] N. A. Galliker and R. M. Trueb, "Value of trichoscopy versus trichogram for diagnosis of female androgenetic alopecia," International Journal of Trichology, vol. 4, no. 1, pp. 19-22, 2012. 
[55] D. Van Neste and R. M. Trueb, "Critical study of hair growth analysis with computer-assisted methods," Journal of the European Academy of Dermatology and Venereology, vol. 20, no. 5, pp. 578-583, 2006.

[56] B. Riedel-Baima and A. Riedel, "Use of the trichoscan to assess female pattern hair loss," Dermatologic Surgery, vol. 35, no. 4, pp. 651-655, 2009.

[57] J. Gassmueller, E. Rowold, T. Frase, and B. Hughes-Formella, "Validation of TrichoScan $®$ technology as a fully-automated tool for evaluation of hair growth parameters," European Journal of Dermatology, vol. 19, no. 3, pp. 224-231, 2009.

[58] J. Kantor, L. J. Kessler, D. G. Brooks, and G. Cotsarelis, "Decreased serum ferritin is associated with alopecia in women," Journal of Investigative Dermatology, vol. 121, no. 5, pp. 985-988, 2003.

[59] D. H. Rushton and I. D. Ramsay, "The importance of adequate serum ferritin levels during oral cyproterone acetate and ethinyl oestradiol treatment of diffuse androgen-dependent alopecia in women," Clinical Endocrinology, vol. 36, no. 4, pp. 421-427, 1992.

[60] L. B. Trost, W. F. Bergfeld, and E. Calogeras, "The diagnosis and treatment of iron deficiency and its potential relationship to hair loss," Journal of the American Academy of Dermatology, vol. 54, no. 5, pp. 824-844, 2006.

[61] A. Bregy and R. M. Trüeb, "No association between serum ferritin levels $>10 \mu \mathrm{g} / \mathrm{l}$ and hair loss activity in women," Dermatology, vol. 217, no. 1, pp. 1-6, 2008.

[62] E. A. Olsen, A. G. Messenger, J. Shapiro et al., "Evaluation and treatment of male and female pattern hair loss," Journal of the American Academy of Dermatology, vol. 52, no. 2, pp. 301-311, 2005.

[63] L. A. Sánchez, M. Pérez, I. Centeno, M. David, D. Kahi, and E. Gutierrez, "Determining the time androgens and sex hormonebinding globulin take to return to baseline after discontinuation of oral contraceptives in women with polycystic ovary syndrome: a prospective study," Fertility and Sterility, vol. 87, no. 3, pp. 712-714, 2007. 


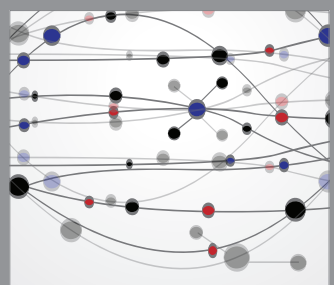

The Scientific World Journal
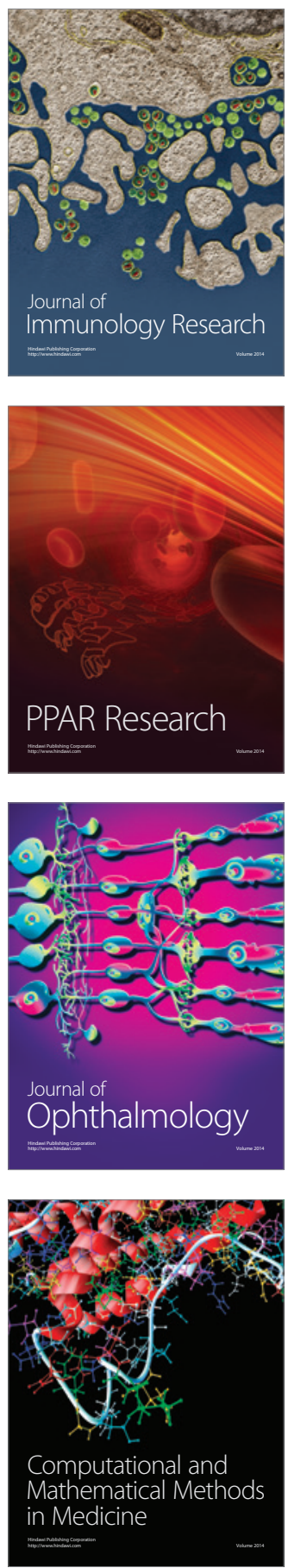

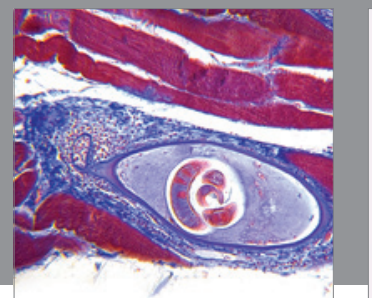

Gastroenterology

Research and Practice
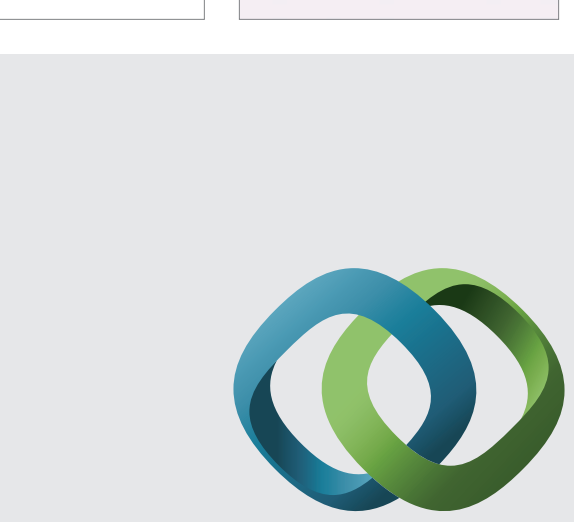

\section{Hindawi}

Submit your manuscripts at

http://www.hindawi.com
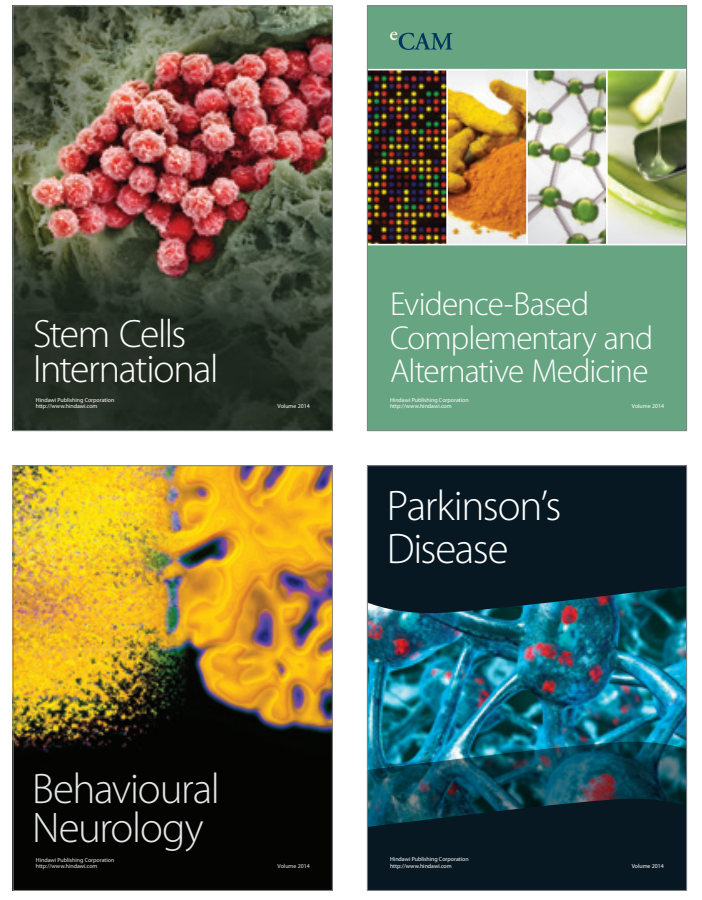
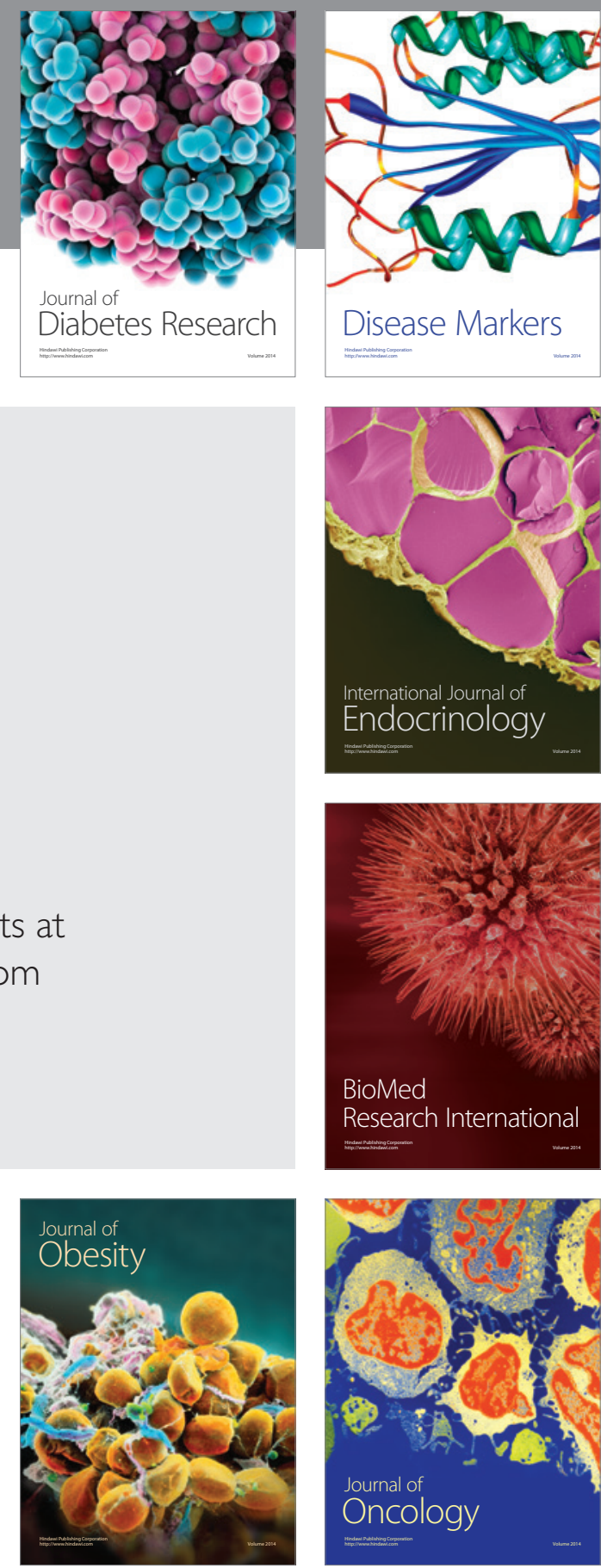

Disease Markers
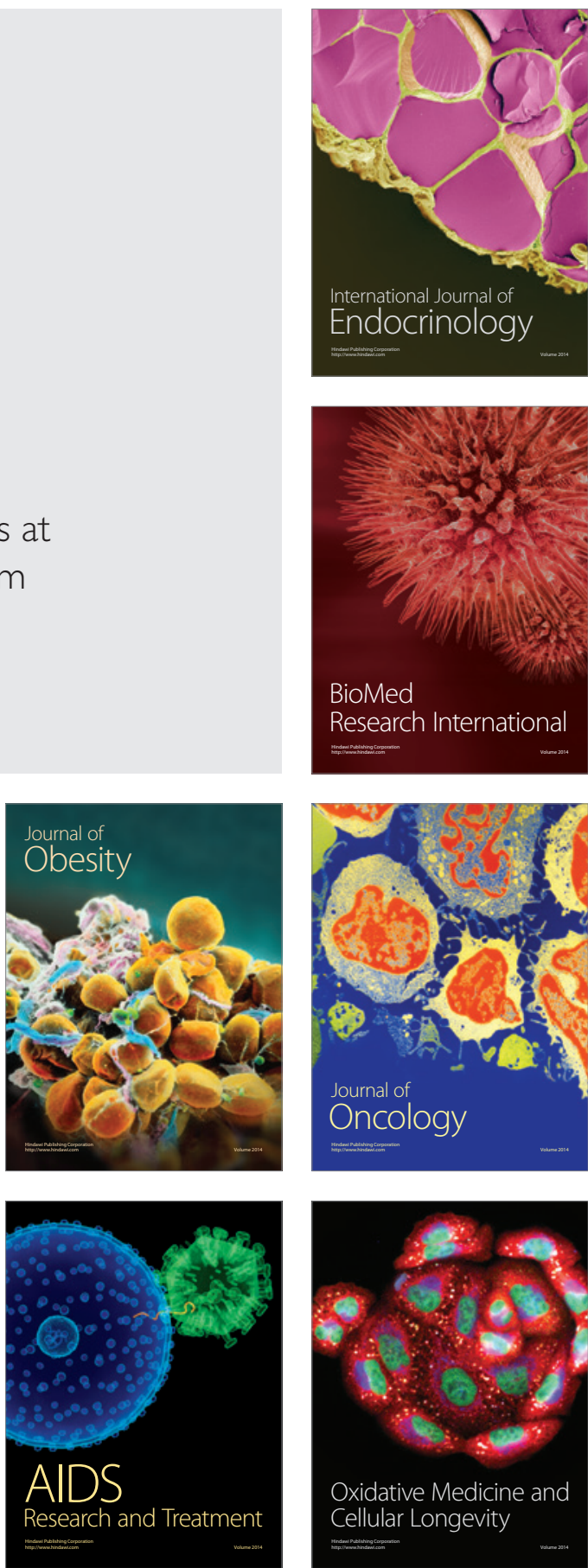